\title{
Nausea and vomiting of pregnancy in an evolutionary perspective
}

\author{
Paul W. Sherman, PhD, and Samuel M. Flaxman, BS \\ Ithaca, $N Y$
}

\begin{abstract}
The proximate mechanisms underlying gestational nausea and vomiting have been intensively studied, but the possibility that the symptoms themselves serve a useful function has only recently been considered seriously. We synthesized evidence to evaluate various hypotheses for the adaptive significance of nausea and vomiting of pregnancy, as well as the possibility that symptoms are nonfunctional byproducts of pregnancy hormones. We found greatest support for the hypothesis that normal levels of nausea and vomiting of pregnancy (excluding hyperemesis) protect pregnant women and their embryos from harmful substances in food, particularly pathogenic microorganisms in meat products and toxins in strong-tasting plants. We discuss the data that support critical predictions of this "maternal and embryo protection hypothesis" (and contradict other hypotheses), as well as appropriate implications of these results. Knowledge that normal nausea and vomiting of pregnancy indicates the functioning of a woman's defense system, rather than a bodily malfunction, may reassure patients and enable health care providers to develop new ways of minimizing the uncomfortable symptoms. (Am J Obstet Gynecol 2002;186:S190-7.)
\end{abstract}

Key words: Adaptation, evolution, prophylaxis, plant toxins, microorganisms, diet

"Morning sickness" is the common term for gestational nausea and vomiting. It is a complete misnomer. The uncomfortable symptoms occur throughout waking hours, not just in the morning, and whereas "sickness" implies disease, healthy women experience the symptoms and bear healthy babies. Nausea and vomiting of pregnancy is more appropriate, descriptive, and objective.

This article briefly summarizes our current understanding of the evolutionary significance of nausea and vomiting of pregnancy. Detailed data and analyses are presented elsewhere. 1,2 The nausea and vomiting of pregnancy symptoms experienced by $90 \%$ to $95 \%$ of women do not fit the definition of "disease" (ie, "a departure from health" or "a condition that impairs a vital function"). Neither are they manifestations of physiological frailty in response to metabolic demands of pregnancy. Rather, nausea and vomiting of pregnancy is an intricate mechanism that probably evolved to serve a useful function: protecting the pregnant woman and embryo from food-borne infections and toxins. Within the normal range of symptoms, nausea and vomiting of pregnancy is appropriately considered as an adaptation. This does not imply that pregnant women should forgo treatment of

From the Department of Neurobiology and Behavior, Cornell University. Support was provided by the National Science Foundation, the Howard Hughes Foundation, the Olin Foundation, and the Agricultural Experiment Station at Cornell University.

Reprint requests: Paul W. Sherman, Department of Neurobiology $\mathcal{E} B$ Behavior, Cornell University, Ithaca, NY 14853.

(C) 2002, Mosby, Inc. All rights reserved.

$0002-9378 / 2002 \$ 35.00+0 \quad 6 / 0 / 122593$

doi:10.1067/mob.2002.122593 debilitating symptoms or avoid eating meats and vegetables. Rather, the implication is that normal levels of nausea and vomiting of pregnancy will not harm the embryo or mother and may even be beneficial to both. We hope this insight will be of some comfort to women experiencing nausea and vomiting of pregnancy and lead to new ways of minimizing the symptoms.

\section{Occurrence}

Across the world, an average of $66 \%$ of pregnant women experience nausea and vomiting of pregnancy, but there is considerable variation among countries (35\% to $84 \%$ of women $\left.{ }^{1}\right)$. Typically, symptoms appear about 5 weeks after the last menstrual period, peak during weeks 8 to 12 , and gradually decline thereafter (Fig 1, a). There is a continuum of symptoms ranging from mild nausea to regular vomiting. ${ }^{3}$ Our focus is on nausea and vomiting of pregnancy symptoms in the "normal" range, excluding hyperemesis gravidarum (excessive, uncontrolled vomiting), which occurs in less than $1 \%$ of all pregnancies. ${ }^{4}$ Obviously we do not consider symptoms that seriously disrupt a pregnant woman's nutrition or physiology to be adaptive.

\section{Cause}

Why does nausea and vomiting of pregnancy occur? As with all questions in biology, this one can be analyzed from multiple perspectives or "levels of analysis." Answers to questions about how the symptoms are brought about (ie, the proximate, physiological mechanisms that underlie nausea and vomiting of pregnancy) and why the symptoms 
occur in the first place (ie, the ultimate, evolutionary significance of nausea and vomiting of pregnancy) are complementary, not mutually exclusive. Complete understanding of any biological phenomenon requires explanations at both proximate and ultimate levels.

The proximate approach is familiar to physicians, whereas ultimate analyses may be somewhat foreign. The promise of the latter is that it will lead to better-informed medical practice because, before attempting to treat (nonpathologic) symptoms, it is helpful to know what the symptoms were "designed" to do. In the case of nausea and vomiting of pregnancy, if we knew why the symptoms occurred (their evolutionary raison d'être) we would be better able to decide whether it always is advisable to eliminate them.

Until recently most research on nausea and vomiting of pregnancy focused on its proximate causes, both hormonal, reviewed by Broussard and Richter ${ }^{3}$ and Fessler, ${ }^{6}$ and genetic, reviewed by Gadsby et al. ${ }^{7}$ We analyzed the probable evolutionary significance of nausea and vomiting of pregnancy, focusing on 2 questions: (1) Why should physiological changes in early pregnancy result in nausea and vomiting instead of other conceivable symptoms? (2) Could nausea and vomiting possibly serve a useful function?

These issues were raised 60 years ago, when Irving ${ }^{8}$ reported that patients with "pernicious vomiting" during pregnancy miscarried less often than those who experienced milder symptoms. Hook ${ }^{9}$ also noted an association between nausea and vomiting of pregnancy and positive pregnancy outcomes. He suggested that nausea and vomiting of pregnancy protects the embryo by reducing maternal ingestion of teratogens, particularly caffeinated beverages, tobacco, and alcohol. More recently, Profet ${ }^{10}$ argued that nausea and vomiting of pregnancy causes pregnant women to expel and learn to avoid an array of food-borne teratogens and abortifacients, especially toxins in strong-tasting vegetables and beverages.

The reasoning underlying the Hook-Profet "embryo protection" hypothesis is as follows. The chemicals that give plants their distinctive aromas and flavors evolved to deter or kill the plants' biotic enemies, such as herbivorous insects and vertebrates, fungi, and bacteria. These protective chemicals are known as "secondary compounds," because they are not essential to the plant's basic metabolism. Every day, we ingest secondary compounds found naturally in plant products. We also use these phytochemicals selectively-for example, when we eat chocolate, drink caffeinated beverages, or cook with spices. In small quantities these compounds can have beneficial effects, ${ }^{11,12}$ but in large quantities they can be allergens, mutagens, carcinogens, teratogens, and abortifacients. ${ }^{13}$ Hook ${ }^{9}$ and Profet ${ }^{10}$ argued that nausea and vomiting of pregnancy has been favored over evolutionary time because it helped protect embryos from dietary toxins.

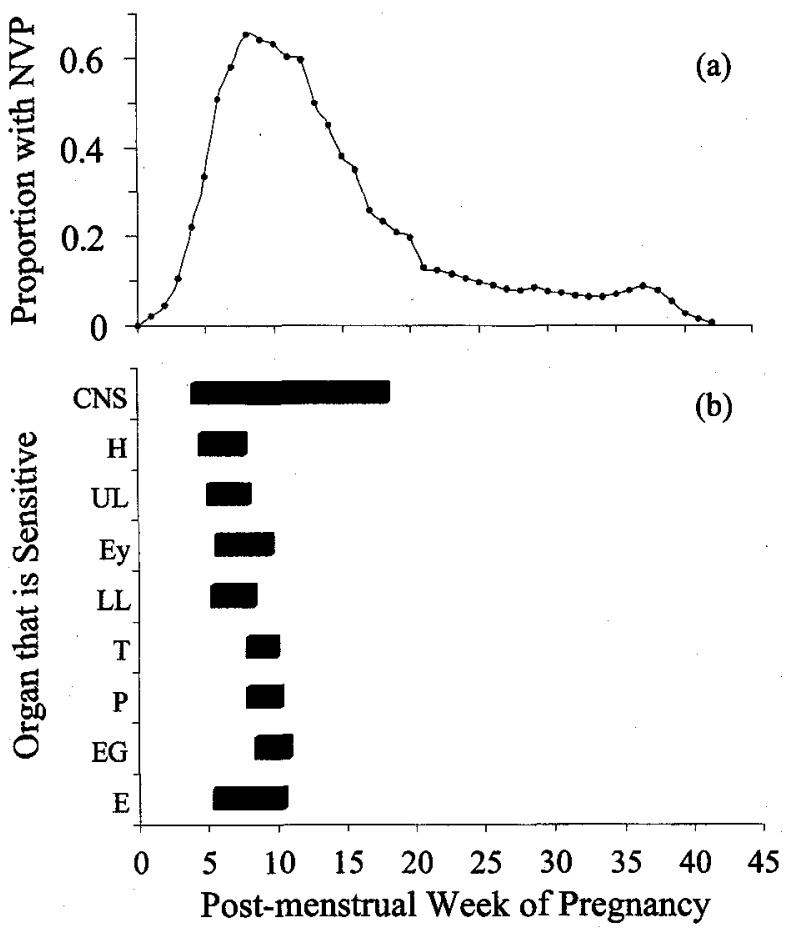

Fig 1. Time course of nausea and vomiting of pregnancy and its relationship to critical periods in embryogenesis. a, Proportion of pregnant women experiencing nausea and vomiting of pregnancy during each post-menstrual week. Data from Vellacott et al. ${ }^{38} \mathrm{~b}$, Critical time periods when various developing tissues are most susceptible to disruption by teratogens; based on information in Moore and Persaud. ${ }^{39} \mathrm{CNS}$, Central nervous system; $H$, heart; $U L$, upper limbs; $E y$, eyes; $L L$, lower limbs; $T$, teeth; $P$, palate; $E G$, external genitalia; $E$, ears. Modified with permission from Flaxman SM, Sherman, PW. Morning sickness: A mechanism for protecting mother and embryo. $Q$ Rev Biol 2000;75: 113-48. Copyright $(02000$ by The University of Chicago. All rights reserved.

However, the embryo is not the only party requiring protection, and plant toxins are not the only dangers in food. The pregnant woman herself is especially susceptible to illnesses because her cell-mediated immune response is depressed ${ }^{6,14}$ Although seemingly counterintuitive, temporary immunosuppression is essential for a successful pregnancy because, to the woman's body, the embryo is like a foreign tissue because half its genome came from the father. If the mother's immune system functioned normally, she might reject her own offspring. ${ }^{15}$ The cost of this adaptive immunosuppression is increasing the woman's susceptibiliy to infectious diseases. ${ }^{16}$

These risks for mothers create even greater dangers for embryos. Miscarriages and birth defects can result if women become seriously ill, especially in the first trimester. ${ }^{17}$ Problematic foods are those that may contain bacteria, fungi, or viruses, especially meats. ${ }^{1,6,18}$ For example, Toxoplasma gondii is a common protozoan parasite 




Fig 2. Food aversions and cravings during gestation based on interviews with 5432 and 6239 women, respectively. Numbers on vertical axis represent average number of aversions or cravings each woman in the sample had to each food category (calculated by dividing total number of aversions or cravings to each category by the total number of women sampled). Triple asterisk indicates significant difference between aversions and cravings for a particular category $(P<.001$, binomial proportions tests), and $N S$ indicates no difference (binomial proportion tests). Food category abbreviations are as follows: Meat, meats, fish, poultry, and eggs; $N-A$, nonalcoholic beverages (including only coffee, tea, and soda, all of which may contain caffeine); Veg, vegetables; $A l c$, alcoholic beverages; $E S S$, ethnic, strong, and spicy foods; $D$, dairy and ice cream; $S$, sweets, desserts, and chocolate; $G \mathcal{E} S$, grains and starches; $F$, fruits and fruit juices. Modified with permission from Flaxman SM, Sherman, PW. Morning sickness: A mechanism for protecting mother and embryo. Q Rev Biol 2000;75: 113-48. Copyright $\odot 2000$ by The University of Chicago. All rights reserved.

that can be acquired by handling or eating raw or undercooked meat. It rarely sickens people unless their immune system is weakened. However, during gestation toxoplasmosis can be quite dangerous: it has been linked to congenital neurologic birth defects, spontaneous abortions, neonatal diseases, 19 and even schizophrenia. 20

Food-borne pathogens are by no means evolutionary novelties. Microorganisms in food would have become problematic for early hominids when they began killing or scavenging game that was too large to consume immediately - that is, about 2.5 million years ago. ${ }^{21}$ Cooking, which probably began 1.9 to 1.6 million years ago, ${ }^{22}$ would reduce pathogen populations in food just before meals. However, the dilemma that faced our ancestors, and that still faces us today, is what to do with the leftoversthat is, scarce, valuable food resources that potentially contain dangerous microorganisms or their toxins. We believe that nausea and vomiting of pregnancy originated and has been maintained as a physiological solution to this problem. Specifically, we hypothesize that nausea and vomiting function to protect the pregnant woman and embryo from food-borne pathogens and dietary toxins.

\section{Testing the maternal-and-embryo-protection hypothesis}

This hypothesis yields 6 critical predictions, which can be evaluated by use of information in the medical, psychological, and anthropological literature. ${ }^{1,2,6}$

Prediction 1. Nausea and vomiting of pregnancy symptoms should peak when the embryo is most susceptible to disruption and the immunovulnerability of the mother and embryo are greatest. Embryonic tissues are most sensitive during certain critical periods when cells are rapidly dividing and differentiating into organs. These sensitive periods start in week 5 , peak during weeks 6 to 12, and end about week 18 (Fig $1, b$ ). In addition, the balance of evidence indicates that maternal immunovulnerability is greatest during the first trimester, so that many foodborne pathogens are most dangerous then. ${ }^{6}$ Consistent with prediction 1 , there is a striking correspondence between the period of sensitivity to both toxins and pathogens and the peak occurrence of nausea and vomiting of pregnancy (Fig 1).

Prediction 2. Foods that pregnant women find aversive should potentially contain plant toxins or pathogenic microorganisms, but foods that are craved should not. Relevant information was obtained from 20 studies of gestational aversions (among 5432 women) and 21 studies of gestational cravings (among 6239 women), on the basis of questionnaires administered to women during pregnancy or soon after parturition. Of 9 major food categories (Fig 2), respondents most often found "meat, fish, poultry, and eggs" to be aversive, followed by "nonalcoholic beverages" (mostly caffeinated) and "vegetables." Consistent with prediction 2, the food categories for which per capita aversions were significantly greater than cravings were the ones most likely to contain microorganisms (ie, meat products) and plant secondary compounds (vegetables, coffee, and tea). Alcohol also was aversive, and it is a well-known teratogen. By contrast, the 4 food categories for which per capita cravings were significantly greater than aversions (Fig 2) were the ones least likely to contain microorganisms or phytochemicals. Fessler ${ }^{6}$ reported a similar pattern of food "taboos" during pregnancy across traditional societies.

Prediction 3. Aversions to foods that potentially contain harmful substances should peak in the first trimester, when embryonic organogenesis is most sensitive to disruption. Cravings and aversions were quantified across all 3 trimesters by MacIntyre ${ }^{23}$ and Rodin and Radke-Sharpe. ${ }^{24}$ Consistent with prediction 3, per capita aversions to all food categories were highest in the first trimester and declined dramatically thereafter. Aversions were significantly more frequent in the first than the second trimester for 6 of 7 food categories, and significantly more frequent in the second than the third trimester for 3 of 7 categories. Also consistent with pre- 
diction 3, women in their first trimester reported significantly more aversions than nonpregnant control subjects to all 7 food categories and, especially, to "meat, fish, poultry, and eggs."

Pregnancy-related food aversions wane rapidly and usually disappear completely after parturition. By contrast, the aversions that men and nonpregnant women develop as a result of food poisoning usually last much longer, sometimes for entire lifetimes. ${ }^{25}$

Prediction 4. Nausea and vomiting of pregnancy should be associated with positive pregnancy outcomes. Information on the relationship between nausea and vomiting of pregnancy and miscarriages (ie, spontaneous abortions during the first 20 weeks) is available from 9 studies involving 22,305 pregnancies. Consistent with prediction 4, in all studies (Fig 3,a) women who experienced nausea and vomiting of pregnancy were significantly less likely to miscarry than women who experienced no symptoms. Two additional studies ${ }^{26,27}$ quantified fetal deaths (miscarriages plus stillbirths), and women who experienced nausea and vomiting of pregnancy were significantly less likely to suffer this outcome. There also was an inverse correlation between the severity of nausea and vomiting of pregnancy symptoms (within the normal range) and the likelihood that pregnancies would terminate in miscarriages (Fig 3,b). Nausea and vomiting of pregnancy symptoms (or lack thereof) did not show any consistent relationship with other types of negative pregnancy outcomes, such as preterm births, low birth weight, or birth defects.

Prediction 5. Expression of nausea and vomiting of pregnancy should depend on diet and should occur least often among women who are seldom exposed to foods that historically contained dangerous substances. Across the world there is considerable variation in frequencies of nausea and vomiting of pregnancy, but there are no studies attempting to relate this variation to frequencies of exposure to dietary triggers (eg, smell, sight, or taste of meats, certain vegetables, or caffeinated beverages). However, information on both the occurrence of nausea and vomiting of pregnancy and diet exists for 27 traditional societies in the Human Relations Area Files. 28 Among these societies there were 7 for which ethnographers specifically noted that nausea and vomiting were rarely or never associated with pregnancy.

Consistent with prediction 5 , these 7 societies were significantly less likely to have meat as a dietary staple and significantly more likely to have only plants as staples than the 20 societies in which nausea and vomiting of pregnancy was observed (Table I). When specific plants were compared, societies lacking nausea and vomiting of pregnancy were significantly more likely to have corn as a staple. Domesticated corn generally has few secondary compounds and dried corn is resistant to microorganisms. Thus women in societies that ate primarily corn may

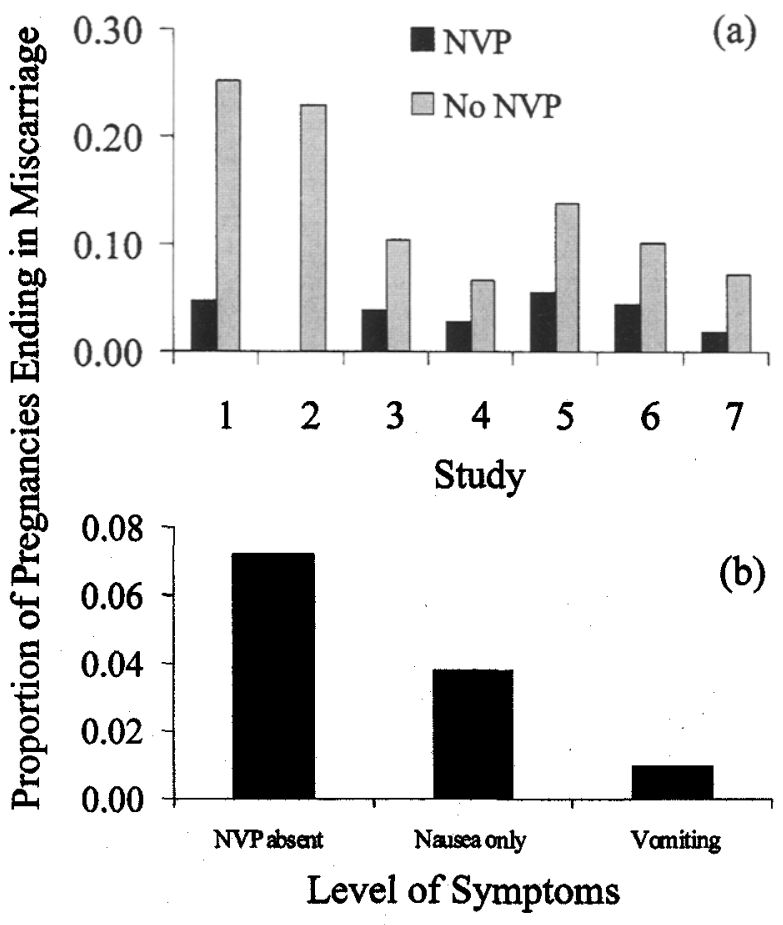

Fig 3. Relationship between nausea and vomiting of pregnancy and rates of miscarriage (spontaneous abortion at $<20$ weeks). Data are from Weigel and Weigel's ${ }^{40}$ metaanalysis of 18,464 pregnancies. a, In each of 7 studies rates of miscarriage were significantly lower in women who experienced nausea and vomiting of pregnancy than those that did not (all $P<.01$ ). Two other studies, 41,42 involving 3841 pregnancies, reported similar, significant results, but data could not be extracted and plotted in same format. b, Severity of nausea and vomiting of pregnancy symptoms experienced was inversely correlated with chance of miscarriage among 903 women $\left(P<.001\right.$; data from Weigel and Weigel. ${ }^{43}$ Modified with permission from Flaxman SM, Sherman, PW. Morning sickness: A mechanism for protecting mother and embryo. Q Rev Biol 2000;75:113-48. Copyright (C) 2000 by The University of Chicago. All rights reserved.

have rarely encountered the foods that trigger nausea and vomiting of pregnancy.

The complete absence of nausea and vomiting of pregnancy in any society is unexpected, and it ought to be confirmed. Unfortunately, however, many of the societies in the Human Relations Area Files sample are now defunct, and those that are extant may consume very different diets today than when they were initially studied. This means that nausea and vomiting of pregnancy may now be common in societies where it was rare historically, providing interesting possibilities for further testing the hypothesis.

Prediction 6. Alleviating nausea and vomiting of pregnancy should leave the embryo more vulnerable to harmful substances in the pregnant woman's diet. Seto et al, ${ }^{29}$ conducted a metaanalysis of 24 studies of women ( $n>$ 200,000) who did and did not take antiemetic drugs in their first trimester. Women who had taken antihistamines were slightly but significantly less likely to bear children 
Table I. Characteristics of diets in traditional societies in relation to nausea and vomiting of pregnancy

\begin{tabular}{lcccc}
\hline $\begin{array}{c}\text { Dietary } \\
\text { characteristic }\end{array}$ & $\begin{array}{c}\text { Number of societies with nausea } \\
\text { and vomiting of pregnancy } \\
(n=20) \text { (proportion) }\end{array}$ & $\begin{array}{c}\text { Number of societies* without } \\
\text { nausea and vomiting of pregnancy } \\
(n=7)(\text { proportion })\end{array}$ & G statistic & Significance level \\
\hline Plants are staples & $20 / 20$ & $7 / 7$ & 0.0 & NS \\
Only plants are staples & $(1.0)$ & $(1.0)$ & 5.3 & $P<.05$ \\
& $7 / 20$ & $6 / 7$ & 4.4 & $P<.05$ \\
Meat is a staple & $(0.4)$ & $1 / 7$ & 7.6 & $P<.01$ \\
Corn is a staple & $12 / 20$ & $(0.1)$ & $6 / 7$ & \\
Rice is a staple & $(0.6)$ & $(0.9)$ & 4.5 & $P<.05$ \\
& $(0.3)$ & $0 / 7$ & $(0.0)$ & \\
\hline
\end{tabular}

${ }^{*}$ Societies in which nausea and vomiting of pregnancy was not observed at the time they initially were studied and their diets at that time, according to records in the Human Area Relations Files. These societies were Bhil, Mbundu, Omaha, Papago, Siriono, Tarahumara, and Woleai.

with birth defects than women who had not taken antihistamines. This finding appears to contradict prediction 6 .

However, the result does not necessarily disconfirm the maternal-and-embryo protection hypothesis. Pregnant women might have already developed protective aversions to potential pathogen- or teratogen-containing foods before nausea and vomiting of pregnancy was suppressed. Also, as Seto et al ${ }^{29}$ themselves noted, the direction of cause and effect is unclear. Antihistamines were taken in response to uncomfortable symptoms. On the one hand, and contrary to our hypothesis, positive outcomes could have been caused by the antihistamines. On the other hand, and consistent with our hypothesis, positive outcomes and antihistamine use could both be effects of the symptoms. Because the studies Seto et $\mathrm{al}^{29}$ analyzed were correlative, these 2 possibilities cannot be disentangled.

\section{Alternative hypotheses}

Three hypotheses alternative to maternal-and-embryoprotection have been proposed. First, nausea and vomiting may be inevitable side-effects of hormone titers associated with viable pregnancies (eg, human chorionic gonadotropin). If so, the symptoms themselves have no function. ${ }^{30}$ However, contrary to this nonadaptive hypothesis, nausea and vomiting of 'pregnancy is neither necessary nor sufficient for a viable pregnancy (at least in developed countries). Among 5235 pregnancies in which nausea and vomiting of pregnancy did not occur only 535 (10\%) resulted in miscarriages, and among 13,192 pregnancies in which nausea and vomiting of pregnancy did occur $509(4 \%)$ resulted in miscarriages nonetheless (data from Fig 3,a). Moreover, viable pregnancies were routine in the traditional societies in which nausea and vomiting of pregnancy reportedly did not occur (Table I). Finally, this hypothesis does not predict or explain the specificity of observed food aversions and cravings (Fig 2).

Second, nausea and vomiting of pregnancy may be a signal, either to a woman's family that she will soon need additional food and protection or to her mate of the desirability of reducing sexual intercourse. ${ }^{31}$ The problem with this "communication" hypothesis is that nausea and vomiting of pregnancy peaks 6 to 10 weeks after conception, which is after other, equally unambiguous but less debilitating indications of pregnancy are apparent (eg, cessation of menstruation, which occurred 4 to 8 weeks earlier). Through evolutionary time, natural selection should have eliminated the uncomfortable symptoms if they were unnecessary. Moreover, intercourse does not affect the viability of a pregnancy, except possibly during the final 4 to 6 weeks before birth, ${ }^{32}$ by which time nausea and vomiting of pregnancy has typically waned (Fig $1, a$ ).

Third, nausea and vomiting of pregnancy may function to reduce energy intake in early pregnancy which, in turn, suppresses maternal tissue synthesis and results in placental weight increases. ${ }^{33}$ Nausea and vomiting of pregnancy thus may help shunt scarce nutrients to the developing placenta. However, contrary to this hypothesis pregnant women crave energy-rich foods and find energy-poor foods aversive (Fig 2).

\section{Nausea and vomiting of pregnancy in other species}

There is anecdotal evidence of nausea and vomiting of pregnancy-like symptoms in only two other mammals, domestic dogs ${ }^{34}$ and rhesus macaques. ${ }^{35}$ Perhaps nausea and vomiting of pregnancy actually is more widespread in nature, but it has not been noticed because of difficulties of detecting symptoms in free-living mammals. Zoo specimens receive bland diets that may not trigger symptoms. Alternatively, wild mammals may be protected in other ways. For example, early in gestation herbivores may avoid the most toxic plants and carnivores may pass up putrefied carrion. In addition, species with more specialized diets than human beings probably have more efficient physiological mechanisms for destroying ingested 
bacteria and fungi and detoxifying plant secondary compounds associated with their preferred foods.

\section{Is nausea and vomiting of pregnancy still useful?}

Nowadays food-borne pathogens are reduced by chemical preservatives and packaging of raw products, cooking and microwaving of meals, and refrigeration and freezing of leftovers. Commercial vegetables typically have minimal secondary compounds because of artificial selection for bland taste (ie, reduction in secondary compounds). In this modern environment is nausea and vomiting of pregnancy just an evolutionary anachronism?

We think not. After all, the relationship between the occurrence of nausea and vomiting of pregnancy and reduced chances of miscarriage has been documented multiple times in the past 50 years (eg, Fig 3). Food-borne bacteria, fungi, viruses, and food-borne toxins still are major health and economic concerns. In the United States alone food-borne illnesses afflict an estimated 80 million people per year ${ }^{36}$ and 1 in 10 Americans experiences bacterial food poisoning annually. 18 Occurrences elsewhere are even greater.

\section{Implications}

Because we are not physicians, it is not appropriate for us to make medical recommendations. However, our results may help health care providers answer some frequently-asked questions about nausea and vomiting of pregnancy:

Question 1. Will normal levels of nausea and vomiting injure a developing embryo? The answer is unequivocally "no." Uncomplicated nausea and vomiting in early pregnancy (ie, excluding hyperemesis gravidarum and pathogenic diseases) will not hurt the embryo. Indeed, nausea and vomiting of pregnancy may help protect the embryo via expulsion of potentially dangerous foods and beverages and creation of temporary taste aversions to them. Pregnant women may derive some comfort from knowing that nausea and vomiting of pregnancy is an intricate, prophylactic mechanism and not a disease. Its occurrence indicates the evolved defenses of their bodies, rather than their "frailty."

Question 2. Should women be concerned if they do not experience nausea and vomiting of pregnancy? Again, the answer is "no." The vast majority of women in western societies have positive pregnancy outcomes regardless of whether they experience nausea and vomiting of pregnancy. Absence of nausea and vomiting of pregnancy does not portend pregnancy failure, and presence of nausea and vomiting of pregnancy does not guarantee success.

Occurrence of "morning sickness" in traditional societies was apparently linked to diet (Table I). This suggests a possible reason some pregnant women in modern societies do not experience the symptoms: their particular home and work environments may not contain the types of foods that were potentially dangerous in evolutionarily antecedent environments. If so, then minimizing exposure to smells and tastes of these substances could reduce the incidence and severity of nausea and vomiting of pregnancy today. This suggests a new, straightforward way to prevent or minimize nausea and vomiting of pregnancy: thoroughly cleaning the home and work environments (eg, walls, draperies, carpets) and keeping them free of potentially triggering odors throughout early gestation-that is, odors from foods that women generally find aversive, such as frying meats and strongsmelling vegetables (Fig 2).

Question 3. Should pregnant women avoid meats and green vegetables because they might contain microorganisms or teratogens? Once again, the answer is "no." Meats and green vegetables contain essential nutrients, and it may be unwise to avoid them entirely. Furthermore, risks from food-borne diseases and toxins have been reduced, especially in developed countries. Nonetheless pregnant women would be well advised to take special care in selecting, preparing, and storing food. Smith $^{17}$ offered some suggestions about how to avoid food-borne illnesses during gestation.

Conversely, however, there is no reason to think that a woman will improve her pregnancy outcome by forcing herself to eat foods to which she has developed aversions. In fact, doing so might have the opposite effect if it exposes her or her embryo to harmful microorganisms or toxins. For most women, the uncomfortable symptoms peak and wane in the first trimester (Fig 1), and aversions do not last throughout pregnancy.

Question 4. Can nausea and vomiting of pregnancy be suppressed without negative consequences? Unfortunately, this cannot yet be answered. On the one hand, eliminating nausea and vomiting of pregnancy potentially leaves the mother and embryo physiologically unprotected. On the other hand, results of the metaanalysis by Seto et $a^{29}$ suggest that chemically eliminating nausea and vomiting of pregnancy does not increase birth defects. We caution, however, that birth defects are only one category of negative pregnancy outcomes, and the direction of cause and effect is unclear in the studies Seto et $\mathrm{al}^{29}$ summarized. Future studies of the effects of antiemetics must control-both before and after treatment-for symptom levels, food aversions, diet, and exposure to food-borne infections and dietary toxins such as alcohol and caffeine.

In general, we question the advisability of blanket recommendations about eliminating nausea and vomiting of pregnancy. The effects of contracting a serious foodborne illness or ingesting toxins during the first trimester can be devastating - far more serious than the discomfort of nausea and vomiting of pregnancy symptoms that do not disrupt nutrition or daily life. Working together, 
physicians and patients must seek an appropriate balance between relief associated with eliminating nausea and vomiting of pregnancy symptoms versus possibly benefiting from their prophylactic effects. Obviously a woman's likelihood of encountering food-borne pathogens and plant toxins during her first trimester, the severity of her symptoms, and their effects on her quality of life play into decisions about ameliorating nausea and vomiting of pregnancy symptoms chemically.

\section{Conclusions}

When we began our inquiries, a key question was whether nausea and vomiting of pregnancy is a cause or a consequence of a viable pregnancy-that is, are nausea and vomiting of pregnancy symptoms themselves functional or just uncomfortable, superfluous side effects of a hormonally mediated tug-of-war between vigorous embryos and mothers over maternal resources? ${ }^{30,} 37$ Our analyses ${ }^{1,2}$ and an independent synthesis of complementary information 6 strongly favor the functional interpretation.

The front-running hypothesis is that nausea and vomiting of pregnancy evolved because it serves a useful function, namely protecting the mother and embryo from foods potentially containing dangerous substances. Prophylaxis is provided by immediate expulsion of the offending foods, reinforced by temporary taste aversions. Thus there are good evolutionary reasons why so many women respond adversely to the sight, smells, or tastes of particular foods and chemicals in early gestation.

Our take-home message is positive: uncomplicated nausea and vomiting of pregnancy is a natural phenomenon and not a disease. In the vast majority of cases, nausea and vomiting of pregnancy is a normal part of a healthy pregnancy. Nausea and vomiting indicate the functioning of the woman's evolved defense system rather than a physiological malfunction. Recognizing nausea and vomiting of pregnancy for what it is-an adaptation-may help reassure patients, as well as enabling health care providers to devise new ways of avoiding or minimizing the uncomfortable symptoms, such as removing potential triggering stimuli (odors) from the home and work environments during early gestation.

We thank Mark E. Hauber and George C. Williams for comments on a preliminary draft, Daniel M. T. Fessler for sharing his preliminary manuscript, and Roberto Romero and Thomas M. Goodwin for inviting us to participate in the NVP Symposium. The order of authorship was determined by a coin flip.

\section{REFERENCES}

1. Flaxman SM, Sherman PW. Morning sickness: a mechanism for protecting mother and embryo. Q Rev Biol 2000;75:113-48.

2. Sherman PW, Flaxman SM. Protecting ourselves from food. Am Sci 2001;89:142-51.

3. Broussard CN, Richter JE. Nausea and vomiting of pregnancy. Gastroenterol Clin North Am 1998;27:123-51.
4. Tsang IS, Katz VL, Wells SD. Maternal and fetal outcomes in hyperemesis gravidarum. Inter J Gynecol Obstet 1996;55:231-5.

5. Sherman PW. The levels of analysis. Ann Behav 1988;36:616-9.

6. Fessler DMT. Reproductive immunosuppression and diet: an evolutionary perspective on pregnancy sickness and meat consumption [plus commentaries]. Curr Anthropol 2002;43:19-61.

7. Gadsby R, Barnie-Adshead AM, Jagger C. Pregnancy nausea related to women's obstetric and personal histories. Gynecol Obstet Invest 1997;43:108-11.

8. Irving FC. The treatment of pernicious vomiting of pregnancy. Virginia Med Monthly 1940;67:717-24.

9. Hook EB. Changes in tobacco smoking and ingestion of alcohol and caffeinated beverages during early pregnancy: are these consequences, in part, of feto-protective mechanisms diminishing maternal exposure to embryotoxins? In: Kelly S, Hook EB, Janrich DT, Porter IH, editors. Birth defects: risks and consequences. New York: Academic Press; 1976. p. 173-83.

10. Profet M. Pregnancy sickness as adaptation: a deterrent to maternal ingestion of teratogens. In: Barkow $\mathrm{JH}$, Cosmides $\mathrm{L}$, Tooby J, editors. The adapted mind: evolutionary psychology and the generation of culture. New York: Oxford University Press; 1992. p. 327-65.

11. Johns $T$. With bitter herbs they shall eat it: chemical ecology and the origins of human diet and medicine. Tucson: University of Arizona Press; 1990.

12. Sherman PW, Billing J. Darwinian gastronomy: why we use spices. BioScience 1999;49:453-64.

13. Beier RC, Nigg HN. Toxicology of naturally occurring chemicals in food. In: Hui YH, Smith RA, Spoerke DG Jr, editors. Foodborne disease handbook. 2nd ed. Volume 3: plant toxicants. New York: Marcel Dekker; 2001. p. 37-185.

14. Formby B. Immunologic response in pregnancy: its role in endocrine disorders of pregnancy and influence on the course of maternal autoimmune diseases. Endocrinol Metab Clin North Am 1995;24:187-205.

15. Haig D. Altercation of generations: genetic conflicts of pregnancy: Am J Reprod Immunol 1996;35:226-32.

16. Brabin BJ. Epidemiology of infection in pregnancy. Rev Infect Dis 1985;7:579-603.

17. Smith JL. Foodborne infections during pregnancy. J Food Protect 1999;62:818-29.

18. Hui YH, Pierson MD, Gorham JR, editors. Foodborne disease handbook. 2nd ed. Volume 1: bacterial pathogens. New York: Marcel Dekker; 2001.

19. Smith JL. Long-term consequences of foodborne toxoplasmosis: effects on the unborn, the immunocompromised, the elderly, and the immunocompetent. J Food Protect 1997;60:1595-611.

20. Torrey EF, Yolken RH. Familial and genetic mechanisms in schizophrenia. Brain Res Rev 2000;31:113-7.

21. deHeinzelin J, Clark JD, White T, Hart T, Renne D, WoldGabriel $\mathrm{G}$, et al. Environment and behavior of 2.5-million-year-old bouri hominids. Science 1999;284:625-9.

22. Wrangham RW, JonesJH, Laden G, Pilbeam D, Conklin-Brittain NL. The raw and the stolen: cooking and the ecology of human origins [plus commentaries]. Curr Anthropol 1999;40:567-94.

23. MacIntyre S. The management of food in pregnancy. In: Murcott A, editor. The sociology of food and eating. Aldershot: Gower Publishing; 1983. p. 57-72.

24. Rodin J, Radke-Sharpe N. Changes in appetitive variables as a function of pregnancy. In: Friedman MI, Tordoff MG, Kare MR, editors. Chemical senses. Volume 4: appetite and nutrition. New York: Marcel Dekker; 1991. p. 325-40.

25. Bernstein IL. Taste aversion learning: a contemporary perspective. Nutrition 1999;15:229-34

26. Klebanoff MA, Koslowe PA, Kaslow R, Rhoads GG. Epidemiology of vomiting in early pregnancy. Obstet Gynecol 1985;66:612-6.

27. Tierson FD, Olsen CL, Hook EB. Nausea and vomiting of pregnancy and association with pregnancy outcome. Am J Obstet Gynecol 1986;155:1017-22.

28. Minturn L, Weiher AW. The influence of diet on morning sickness: a cross-cultural study. Med Anthropol 1984;8:71-5.

29. Seto A, Einarson T, Koren G. Pregnancy outcome following first trimester exposure to antihistamines: meta-analysis. Am J Perinatol 1997;14:119-24.

30. Forbes S. Pregnancy sickness and embryo quality. Trends Ecol Evol 2002;17:115-20. 
31. Deutsch JA. Pregnancy sickness as an adaptation to concealed ovulation. Riv Biol 1994;87:277-95.

32. Pritchard JA, MacDonald PC. Williams' obstetrics. 16th ed. New York: Appleton-Century-Crofts; 1980.

33. Huxley RR. Nausea and vomiting in early pregnancy: its role in placental development. Obstet Gynecol 2000;95:779-82.

34. Bebiak DM. Nutrition and the reproductive roller coaster. Proc Ann Mtng Soc Theriogen 1988;1988:167-73.

35. Czaja JA. Food rejection by female rhesus monkeys during the menstrual cycle and early pregnancy. Physiol Behav 1975;14:579-87.

36. World Health Report. The state of world health. Geneva: World Health Organization; 1996.

37. Haig D. Genetic conflicts in human pregnancy. Q Rev Biol 1993;68:495-532.
38. Vellacott ID, Cooke EJA, James CE. Nausea and vomiting in early pregnancy. Int J Gynecol Obstet 1988;27-57-62.

39. Moore KL, Persaud TVN. The developing human: clinically oriented embryology. 6th ed. Philadelphia: WB Saunders; 1998.

40. Weigel RM, Weigel MM. Nausea and vomiting of early pregnancy and pregnancy outcome. A meta-analytical review. $\mathrm{Br} \mathrm{J}$ Obstet Gynaecol 1989;96:1312-8.

41. Petitti DB. Nausea and pregnancy outcome. Birth 1986;13:223-6.

42. Fenster L, Eskenazi B, Windham GC, Swan SH. Caffeine consumption during pregnancy and spontaneous abortion. Epidemiology 1991;2:168-74.

43. Weigel RM, Weigel MM. Nausea and vomiting of early pregnancy and pregnancy outcome. An epidemiological study. Br J Obstet Gynaecol 1989;96:190411. 